CAE Working Paper \#02-08

Introduction to Sunspots and Lotteries

by

Edward Prescott

and

Karl She 11

August 2002 


\title{
Introduction to Sunspots and Lotteries
}

\author{
Edward C. Prescott \\ Department of Economics, University of Minnesota, Minneapolis, Minnesota \\ 55455; and \\ Research Department, Federal Reserve Bank of Minneapolis, Minneapolis, \\ Minnesota 55480 \\ prescott@econ.umn.edu \\ and \\ Karl Shell \\ Department of Economics, Cornell University, 402 Uris Hall, Ithaca, New York \\ 14853-7601 \\ ks22@cornell.edu
}

Version: August 24, 2002

This introduces the symposium on sunspots and lotteries. Two stochastic generalequilibrium concepts, Sunspot Equilibrium (SE) and Lottery Equilibrium (LE), are compared. It is shown that, for some general, pure-exchange economies which allow for consumption non-convexities or moral hazards, the set of LE allocations is equivalent to the set of SE allocations provided that the randomizing device can generate events of any probability. Journal of Economic Literature classification numbers: D51, D82, D84, E32.

What are the connections between sunspot equilibrium (SE) and lottery equilibrium (LE)? Both SE and LE are general equilibrium concepts in which extrinsic uncertainty plays an essential role. Uncertainty is said to be extrinsic if it does not affect the economic fundamentals (such as preferences, endowments, and technologies). The sole purpose of extrinsic uncertainty is to introduce randomization into allocations. The initial histories of and motivation for SE and LE are quite different.

"Sunspots" were introduced by Cass and Shell ${ }^{1}$ to explain "excess market volatility." The earliest SE models were based on standard, convex overlapping-generations economies in which rational agents condition their expectations on an extrinsic random variable called "sunspots." These expectations are self-fulfilling, thus showing how the market economy can generate uncertainty (in addition to transmitting uncertainty about the fundamentals). These SE allocations are necessarily inefficient in strictly convex economies because a feasible allocation in which sunspots matter can always be Pareto dominated in such a setting by an allocation in which sunspots are ignored.

Lotteries were introduced into general equilibrium theory by Prescott and Townsend ${ }^{2}$ to model the market allocation of resources in situations with moral hazards. The Prescott and Townsend lottery equilibria assume large economies with a finite number of types, though extensions to an infinite number of types are possible in essentially the same way extensions are carried out for standard Arrow-Debreu

\footnotetext{
${ }^{1}$ See Shell [37] and Cass and Shell [5].

${ }^{2}$ See Prescott and Townsend [31, 32].
} 
economies. ${ }^{3}$ With expected utility maximization and continuous utility, all the standard results for finite agent convex economies hold. In particular, the first and second welfare theorem and the standard existence arguments are valid. ${ }^{4}$ An advantage of the LE approach is that the LE economies are convex and therefore easily dealt with using standard general equilibrium tools. An advantage of using a continuum of economic agents is that the modeler can ignore the names of the agents. Names do not matter in applied analyses as economic statistics are reported on an anonymous basis for categories of people and it is a legal principle that policies are anonymous.

Rogerson [35] considered an economy with a labor indivisibility. The competitive equilibrium allocation for his economy without a randomizing device is efficient by the first welfare theorem. However, if there is a randomizing device, the economy is different and the competitive allocation for the economy without a randomizing device is not efficient in the economy with a randomizing device. Shell and Wright [40] identified the same phenomenon in SE economies. From the results of Garratt, Keister, Qin and Shell [14] and Kehoe, Levine, and Prescott [24], we know that, for the perfect-market economies treated in this symposium, SE allocations are efficient because they yield the same utilities as efficient LE allocations. In fact, it is easy to see that the first welfare theorem also applies directly to the sunspots economies treated in this symposium. Thus it is important to bear in mind the distinction between introducing sunspots into an underlying economy where the first welfare theorem does not hold (due to, say, market imperfections or the double infinity of commodities and consumers in the overlapping-generations model) and introducing sunspots to allow for welfare-improving randomization when nonconvexities are present. The papers in this symposium focus on the latter approach.

The sunspots economy is typically constructed from the corresponding certainty economy ${ }^{5}$ by (1) introducing an extrinsic randomizing device, i.e. a set of extrinsic states of nature and a probability measure over the states, and (2) expanding the commodity and the technology sets to accommodate the extrinsic states of nature. For example, if the number of sunspots states is $S$, and $X_{h}, Y_{f}$, and $\omega_{h}$ are respectively consumption sets, production sets, and endowments in the underlying (usually) certainty economy, then the Cartesian products

$$
\begin{aligned}
\left(X_{h}\right) \times \cdots \times\left(X_{h}\right) & =\left(X_{h}\right)^{S}, \\
\left(Y_{f}\right) \times \cdots \times\left(Y_{f}\right) & =\left(Y_{f}\right)^{S},
\end{aligned}
$$

and

$$
\left(\omega_{h}\right) \times \cdots \times\left(\omega_{h}\right)=\left(\omega_{h}\right)^{S},
$$

are respectively the consumption sets, the production sets, and the endowments for the sunspots economy. Hence technologies and endowments are independent of sunspots. It is also assumed that preferences are suitably symmetric with respect to sunspot states. ${ }^{6}$ Goods prices depend on the realized state of nature (e.g. the

\footnotetext{
${ }^{3}$ Following the extension of Mas Colell [26], and Jones [23] to a continuum of differentiated commodities, the commodity space is signed measures.

${ }^{4}$ Like in Debreu [10], the commodity space has infinite dimesion, but the economy is convex and the number of types finite.

${ }^{5}$ In general, the underlying economy need not be a certainty economy. It might include intrinsic uncertainty.

${ }^{6}$ Von Neumann-Morgenstern preferences are consistent with extrinsic uncertainty, but these are not the only preferences consistent with extrinsic uncertainty. See Balasko [4], for a general, abstract definition of extrinsic uncertainty.
} 
price of chocolate in sunspot state $\alpha$ ). There might also be securities contingent upon the sunspot state (e.g. chocolate to be delivered in state $\alpha$, or dollars to be delivered in state $\beta$ ). Some SE models allow for state-contingent securities; others do not. Hence the sunspots economy is the special case (for which there is extrinsic uncertainty) of an Arrow-Debreu economy. The pure sunspots economy can be viewed as the limit economy, in which the effects on the fundamentals of intrinsic uncertainty are small. ${ }^{7}$ In the SE model, the extrinsic states of nature are essential. In principle, it is possible for the price of a given bundle in one state to differ from the price of the same bundle in another state, even if the two states are equally probable: the law-of-one-price applies to a given commodity or commodity bundle in a given state.

In the lottery economy, the commodity space is the space of signed measures on the Borel sigma algebra of the underlying consumption sets. Instead of buying and selling goods, agents buy and sell probabilities of points in the underlying commodity space. Each consumer spreads extrinsic probability over points in the commodity space so as to maximize his ex-ante expected utility subject to incentive and other constraints as well as affordability. ${ }^{8}$ In an LE world, a given bundle delivered with a given probability is the basic commodity to which the law-of-one-price applies. A firm that buys or sells these measures must have a randomizing device, but it trades in probabilities, not states. For example if each of ten customers has a one-tenth probability of receiving the good, then the randomizing device must generate ten exclusive events each with probability one-tenth. (There is, of course, the usual Arrow-Debreu event-contingent trading where the event in question affects the technology or preferences or both.)

The early LE and the early SE models also differ in their capacities for coordinating stochastic allocations. Consider, for example, an economy with an integer number $N$ units of an indivisible good and $2 N$ consumers. One possible allocation is that each individual receive one unit of the indivisible good with probability $\frac{1}{2}$. This stochastic allocation would be feasible if the probabilities were coordinated to ensure that ex post no more than half of the population is receiving the indivisible good. In the SE model, this coordination is guaranteed through market clearing in extrinsic-state-dependent contracts. In the example, half the population would hold contracts for delivery of one unit of the indivisible good in a state that occurs with probability $\frac{1}{2}$, while the other half would hold contracts for delivery of one unit of the good in another (mutually exclusive) state that also occurs with probability $\frac{1}{2}$. The early SE models were based on a finite sunspot-state space and either a finite number of consumers or a countably infinite number of consumers from the overlapping-generations model. The early (and indeed most of the) LE models were based on a continuum of consumers and continuous probability. Because of the "law of large numbers," coordination is not necessary with a continuum of agents. Hence in the early LE models, stochastic allocations could be determined by simple (uncoordinated) individual coin flips.

Kenneth Arrow appears to be the first to have suggested that there is a connection between LE allocations and SE allocations. According to Prescott and

\footnotetext{
${ }^{7}$ See Manuelli and Peck [27]

${ }^{8}$ The set-up is simpler in actual applications of the LE approach, where the focus has been on cases in which the underlying consumption set can be reduced to a finite number of bundles. Then the LE consumption set can be viewed as the set of probability measures over these bundles. In these cases, LE can be computed as a standard linear programming problem. See Townsend [42] and Prescott and Townsend [34].
} 
Townsend, ${ }^{9}$ Arrow conjectured that the LE allocations in the Prescott and Townsend [31] paper could be implemented as SE allocations. Shell and Wright [40] picked up on this point. In their study of sunspots and indivisible goods, they showed that the LE allocations in the Rogerson [35] and Hansen [18] indivisible work-effort models can be implemented as SE allocations.

The Hansen and Rogerson models, like all LE models up till then, were based on a continuum of agents. Garratt [12] extended the Prescott-Townsend LE model to allow for a finite number of agents. Since the "law of large numbers" does not apply in the finite case, Garratt had to give the LE auctioneer a role in coordinating probabilities. In the extended LE model, feasibility of an allocation also requires that each individual lottery be the marginal distribution of some common joint lottery. In the example, each agent holds a lottery ticket that pays off with probability $\frac{1}{2}$ but the auctioneer coordinates the individual lotteries so that ex post only half of the tickets are winners. ${ }^{10}$ In a model with nonconvexities in consumption, a finite number of underlying commodities, a finite number of agents, and complete markets, Garratt [12] showed that every Prescott-Townsend-Garratt LE allocation can be implemented as an SE allocation, but not all SE allocations are LE allocations. For Garratt [12], the LE model was implicitly based on a continuous randomizing device, while the probability device for the SE model was variable. Not all SE allocations based on a finite randomizing device are also SE allocations in the continuous randomizing device case. ${ }^{11}$ What if we compare the LE allocations with SE allocations in which the common randomizing device is continuous, so that there can be events for every probability?

In their paper in this symposium, Garratt, Keister, Qin, and Shell [14] analyze a pure-exchange economy with a finite number of consumers with possible nonconvexities in preferences and consumption sets, symmetric information, a common continuous randomizing device, and perfect markets. Their principal result is that in this environment equilibrium allocations can be supported by sunspot-contingent prices that are co-linear with sunspot probabilities. This result extends to the case with a finite number of equally probable sunspot states, but it does not extend to more general discrete probability devices. Garratt, Keister, Qin and Shell use their result on SE prices to show that the set of LE allocations is the same as the set of SE allocations based on a continuous, or unconstrained, sunspots device, one that can generate events of any probability.

In their paper in this symposium, Kehoe, Levine, and Prescott [24] analyze pure-exchange economies with a continuum of agents, private information, indivisibilities, and a randomizing device that can generate events of any probability. They show that any sunpots competitive equilibrium allocation can be supported by a lottery equilibrium with the ex-post distribution of consumptions over individuals and ex-ante expected utilities being the same. They also show how to support a

\footnotetext{
${ }^{9}$ See Prescott and Townsend [31], page 18.

${ }^{10}$ The joint lottery constructed by the auctioneer performs the same role as the sunspots variable in that it assigns probabilities to events in which the different (feasible) pure allocations occur. However, agents are not allowed to make trades conditional on these events (they are known only by the auctioneer) and hence the extended lottery model is different from the sunspots model where extrinsic-state contingent trades are allowed. For more on this see Garratt, Keister, and Shell [15].

${ }^{11}$ In fact, some SE based on a finite sunspot device do not survive refinement of the state space to (finer) finite partitions. The question of whether SE are robust to all refinements of the state space (finite or continuous) is studied in Goenka and Shell [16] and Garratt and Keister [13]. See Antinolfi and Keister [3] for a related notion called strong sunspot immunity.
} 
lottery equilibrium allocation as a sunspot equilibrium. In addition, they establish that with decreasing absolute risk-aversion and no indivisibilities, proper lotteries (i.e. lotteries in which not all probabilities are zero or one) are not employed in equilibrium. They provide a numerical example with increasing absolute risk-aversion in which proper lotteries are actively employed in equilibrium.

Generalizing results of Hansen [18], they show that there is a stand-in household for each type and that each of these stand-ins have convex, continuous preferences on the traded goods. All uncertainty is dealt with within the household or, equivalently, through a mutual insurance arrangement. In the Hansen example, the stand-in household sells a number of workweeks of the standard length and services of capital and buys the consumption and investment good. The randomization as to how much each member of the stand-in household consumes and whether he works is done within the stand-in household. Unlike the Prescott-Townsend framework, there are empirical counterparts of the traded commodities and the national income and product accounts for the model economies can be constructed.

What if the lotteries and the sunspot states are restricted to those that can be generated from the same underlying, finite probability device? For the LE from this constrained model, there is in equilibrium a unique price for any feasible probability, but prices are not necessarily linear in probabilities. For the SE from this restricted model, there is in equilibrium a unique price for each feasible event, prices are linear in events, but the price of a given probability is not necessarily unique. In an unpublished paper, Garratt, Keister, and Shell [15] provide examples of SE allocations based on finite randomizing devices that are not LE allocations. Nonetheless, Garratt, Keister, and Shell [15] show that for most finite randomizing devices the set of LE allocations and the set of SE allocations are equivalent.

Despite very different histories and different motivations, it turns out that lottery equilibrium and sunspot equilibrium lead to essentially the same competitive allocations for the special environment analyzed in this symposium: namely, economies with a finite number of individual types, no distortions and an unconstrained randomizing device (which can generate events with any probability). Even when there is equivalence of allocations, it is worthwhile to retain both equilibrium concepts: each has its own strengths. For example, Garratt and Keister [13] show how an open question regarding the robustness of sunspot equilibria is easily solved by looking at the lottery formulation of the problem. The SE approach is based on the familiar contingent-commodities approach, and as such is easily applied to a wide variety of settings. On the other hand, the LE approach appears to provide a better basis for computing equilibria. For example, in computing LE with indivisible goods, one faces a relatively simple linear-programming problem $^{12}$ rather than the full-blown non-linear integer-programming problem that would seem to arise in computing SE. The implementation of the continuum of individual specific lotteries so as to guarantee that actual and expected payouts are equal absent private information is straightforward. ${ }^{13}$ For sufficiently large but finite numbers of individuals with $L_{2}$ preferences, the approximation is arbitrarily good even with private information. ${ }^{14}$

The LE approach has also been applied to the "nonconvexities" arising because of incentive constraints in the consumption set. Cole [7] points out that lotteries sometimes do more than just convexify private information economy. He shows

\footnotetext{
${ }^{12}$ See Prescott [33] for an excellent survey.

${ }^{13}$ See Anderson [2] and Green [17].

${ }^{14}$ See Uhlig [43].
} 
that absent lotteries the private informaton economy of Prescott and Townsend [31] is convex, yet lotteries are needed for the Pareto efficiency. In addition, the LE concept has also been applied to real nonconvexities arising in labor markets because a given person can only supply one type of workweek and workweeks can be of many lengths. The Hansen [18], Rogerson [35], and Shell and Wright [40] applications all have the constraint that each individual either works full time or not at all. Hansen and Sargent [19] have regular time as well as overtime workweek lengths. Hornstein and Prescott [22] and Alpanda [1] endogenize this workweek, permitting it to take any length. This extension is used by Kydland and Prescott [25] in their study of U.S. business cycles and by Cole and Ohanian [8] and Hayashi and Prescott [20] in their studies of great depressions. Fitzgerald [11] uses the construct, but with multiple skill types, to study the distributive and efficiency consequences of policies that constrain the workweek length . Osuna and Rios-Rull [29] study the problem of implementing a 35 hour work week using an overtime tax.

Cole and Prescott [9] apply the LE concept to clubs, where there the commodity point must be indexed by individual and club type. Caucutt [6] applies the club concept to model the consequence of peer group effects in schooling if schooling is competitively provided. Prescott and Townsend [34] model firms using clubs in general equilibrium. Prescott and Rios-Rull [30] use lotteries in a search model to overcome the non-convexity arising due to the fact that a person can only be at one place at a given point in time. Lotteries play a role in mechanism design going back to Myerson [28], Harris and Townsend [21], and Prescott and Townsend [31, 32]. An important paper on LE and mechanism design is Townsend [42].

The SE concept has been applied in a wide variety of economic settings starting with overlapping-generations models. The extensive SE literature (both theoretical and applied) has been reviewed in Shell [38], Shell and Smith [39], and most recently in Spear and Wright [41]; we do not provide a systematic review here. Sources of proper sunspot equilibria include: the overlapping-generations "double-infinity" of consumers and dated commodities ${ }^{15}$, restricted market participation (as naturally arises in OG and other economies), missing markets and other budget restrictions, money and other sources of "indeterminacy", imperfect competition, externalities (an important case of missing markets), private information, non-convexities, regulatory restrictions, bounded rationality, and optimal banking mechanisms.

In much of the literature, sunspot equilibrium provides "symmetry-breaking" because proper SE are in these cases asymmetric outcomes in symmetric economies. These SE reflect the uncertainty generated by the market economy. These SE are typically non-optimal. They are often instances of indeterminacy of equilibria. With non-convexities (the focus of the present symposium), sunspots (and lotteries) can move the economy from asymmetric outcomes to symmetric outcomes. Hence, in the non-convex case SE (and LE) can be "symmetry-making".

\section{REFERENCES}

[1] S. Alpanda, Workweek variation in representative agent models, mimeo, University of Minnesota, 2002.

[2] R. M. Anderson, "Nonstandard analysis with applications to economics" in Handbook of Mathematical Economics 4 (W. Hildenbrand and H. Sonnen-

${ }^{15}$ The importance of the role of the double-infinity in OG models was identified by Shell [36]. 
schein, eds.), Amsterdam: North-Holland Publishing Company, 1991, pp. $2145-2208$.

[3] G. Antinolfi and T. Keister, Options and sunspots in a simple monetary economy, Econ.Theory 11 (1998), 295-315.

[4] Y. Balasko, Extrinsic uncertainty revisited, J. Econ. Theory 31 (1983), 203210.

[5] D. Cass and K. Shell, Do sunspots matter? J. Polit. Econ. 92 (1983), 193-227.

[6] E. Caucutt, Peer group effects in applied general equilibrium, Econ. Theory 17 (2001), 25-51.

[7] H. L. Cole, General competitive analysis in an economy with private information: comment, Intern. Econ. Rev. 30 (1989), 249-252.

[8] H. L. Cole and L. E. Ohanian, The great U.K. depression: a puzzle and possible resolution, Review Econ. Dyn. 5 (2002), 19-44.

[9] H. L. Cole and E. C. Prescott, Valuation equilibria with clubs, J. Econ. Theory 74 (1997), 19-39.

[10] G. Debreu, Valuation equilibrium and pareto optimum, Proceedings of the National Academy of Science 40 (1954), 588-92.

[11] T. J. Fitzgerald, Work schedules, wages and employment in a general equilibrium model with team production, Review Econ. Dyn. 1 (1998), 809-34.

[12] R. Garratt, Decentralizing lottery allocations in markets with indivisible commodities, Econ. Theory 5 (1995), 295-313.

[13] R. Garratt and T. Keister, A characterization of robust sunspot equilibria, $J$. Econ. Theory, doi:10.1006/jeth.2001.2798, 107 (2002), XXX-XXX.

[14] R. Garratt, T. Keister, C.-Z. Qin, and K. Shell, Equilibrium prices when the sunspot variable is continuous, J. Econ. Theory, doi:10.1006/jeth.1999.2634, 107 (2002), XXX-XXX.

[15] R. Garratt, T. Keister, and K. Shell, "Comparing sunspot equilibrium and lottery equilibrium allocations: the finite case," mimeo., Cornell University, June 21, 2002.

[16] A. Goenka and K. Shell, Robustness of sunspot equilibria, Econ. Theory 10 (1997), 79-98.

[17] E. Green, "Lending and the smoothing of uninsurable income" in Contractual Arrangements for Intertemporal Trade (E. C. Prescott and N. Wallace, eds.), Minneapolis: University of Minnesota Press, 1987, pp. 3-25.

[18] G. D. Hansen, Indivisible labor and the business cycle, J. Mon. Econ. 16 (1985), 309-328.

[19] G. D. Hansen and T. J. Sargent, Straight time and overtime in equilibrium, J. Mon. Econ. 21 (1988), 281-308. 
[20] F. Hayashi and E. C. Prescott, The 1990s in Japan: a lost decade, Review Econ. Dyn. 5 (2002), 206-35.

[21] M. Harris and R. M. Townsend, "Resource allocation under asymmetric information. Econometrica 49 (1981), 33-64.

[22] A. Hornstein and E. C. Prescott, "The firm and the plant in general equilibrium theory" in General Equilibrium and Growth: The Legacy of McKenzie (R. Becke, M. Boldrin, R. Jones, and W. Thompspn, eds.), New York: Academic Press, 1993, pp. 393-410.

[23] L. E. Jones, A competitive model of commodity differentiation, Econometrica $\mathbf{5 2}(1984), 507-30$.

[24] T. Kehoe, D. K. Levine, and E. C. Prescott, Lotteries, sunspots, and incentive constraints, J. Econ. Theory, doi:10.1006/jeth.2001.2792, 107 (2002), XXXXXX.

[25] F. E. Kydland and E. C. Prescott, Hours and employment variation in business cycle theory, Econ. Theory 1 (1991), 63-81.

[26] A. Mas-Colell, A model of equilibrium with differentiated commodities, $J$. Math. Econ. 2 (1975), 263-295.

[27] R. Manuelli and J. Peck, Sunspot-like effects of random endowments, J. Econ. Dyn.Cont. 16 (1992), 193-206.

[28] R. Myerson, Optimal coordination mechanisms in generalized principal-agent problems, J. Math. Econ. 10 (1982), 67-81.

[29] V. Osuna and J. V. Rios-Rull, Implementing the 35 hour workweek by means of overtime taxation, mimeo., University of Pennsylvania, 2001.

[30] E. C. Prescott and J.-V. Rioss-Rull, Classical competitive analysis of economies with islands, J. Econ. Theory 57 (1992), 73-98.

[31] E. C. Prescott and R. M. Townsend, General competitive analysis in an economy with private information, Intern. Econ. Rev. 25 (1984), 1-20

[32] E. C. Prescott and R. M. Townsend, Pareto optima and competitive equilibria with adverse selection and moral hazard, Econometrica 52 (1984), 21-45.

[33] E. S. Prescott, A primer in moral-hazard models, Federal Reserve Bank of Richmond Economic Quarterly 85 (1999), 47-77.

[34] E. S. Prescott and R. M. Townsend, Collective organizations versus relative performance contracts: inequality, risk sharing, and moral hazard, J. Econ. Theory 103 (2002), 283-310.

[35] R. Rogerson, Indivisible labor, lotteries and equilibrium, J. Mon. Econ. 21 (1988), 3-16.

[36] K Shell, Notes on the economics of infinity, J. Polit. Econ. 79 (1971), 10021011. 
[37] K. Shell, "Monnaie et allocation intertemporelle," [title and abstract in French, text in English] mimeo, Séminaire Roy-Malinvaud, Centre National de la Recherche Scientifique, Paris, November 21, 1977. Translation to be published in Macroeconomic Dynamics as a Vintage Unpublished Paper.

[38] K. Shell, "Sunspot equilibrium" in The New Palgrave: A Dictionary of Economics (J. Eatwell, M. Milgate, and P. Newman, eds.), Vol. 4, pp.274-280, Macmillan, New York, 1989.

[39] K. Shell and B. Smith, "Sunspot equilibrium" in The New Palgrave Dictionary of Money and Finance (J. Eatwell, M. Milgate, and P. Newman, eds.), Vol. 3, pp.601-605, Macmillan, London, 1992.

[40] K. Shell and R. Wright, Indivisibilities, lotteries, and sunspot equilibria, Econ. Theory 3 (1993), 1-17.

[41] S. E. Spear and R. Wright, "An interview with Karl Shell", Macroecon. Dyn. 5 (2001), 701-741.

[42] R. M. Townsend, "Arrow-Debreu programs as microfoundations of macroeconomics" in Truman F. Bewley (ed.) Advances in Economic Theory, Cambridge: Cambridge University Press, 1987.

[43] H. Uhlig, A law of large numbers for large economies, Econ. Theory 8 (1996), 41-50. 